\title{
Overview of Parameters Influencing Biomass and Bioreactor Performance Used for Extracellular Ligninase Production from Phanerochaete chrysosporium
}

\author{
Seteno Ntwampe ${ }^{1 *}$, Faysol Chowdhury ${ }^{2}$ Marshall Sheldon $^{2}$ and Heinrich Volschenk $^{3}$ \\ ${ }^{1}$ Department of Agriculture and Food Sciences; ${ }^{2}$ Department of Chemical Engineering; Cape Peninsula University \\ of Technology; P.O. Box 652; Cape Town, 8000; South Africa. ${ }^{3}$ Department of Microbiology; University of \\ Stellenbosch; P/Bag X1; Matieland, 7602; South Africa
}

\begin{abstract}
The production of extracellular enzymes is gaining momentum as commercial interests seek alternative ways to improve the productivity in the biotechnology and pharmaceutical industries. Early research studies looked at improving batch bioreactor operational challenges; however, the use of continuous cultures was indicated to be favourable. This led to a new approach developed to produce extracellular enzymes continuously using fixed-film bioreactors from biofilms immobilised on polymeric and inorganic membranes. In this review, the performance of P. chrysosporium biomass, evaluated in terms of ligninase production using different bioreactor operation conditions, is highlighted. Furthermore, the limitations related to the implementation of optimised batch culture conditions to continuous fixed-film bioreactors are discussed. DO transportation, trace element toxicity and lipid peroxidation effects on $P$. chrysosporium biomass in fixed-film bioreactors operated for elongated periods, are also discussed.
\end{abstract}

Key words: Phanerochaete chrysosporium, lignin peroxidase, manganese peroxidase, dissolved oxygen, bioreactors

\section{INTRODUCTION}

The white-rot fungus (WRF), Phanerochaete chrysosporium, is well-known for its capability of degrading lignin to carbon dioxide $\left(\mathrm{CO}_{2}\right)$, water $\left(\mathrm{H}_{2} \mathrm{O}\right)$ and hydrogen peroxide $\left(\mathrm{H}_{2} \mathrm{O}_{2}\right)$. Apart from the fact that the fungus exhibits high rates of lignin degradation, it is also characterised by rapid growth in liquid cultures and rapid sporulation when immobilised on carriers (Gold and Alic, 1993). The fungus is classified as white-rot, because it causes a form of wood decay, which results in the bleaching of wood (Eaton and Hale, 1993). WRF are members of the Enmycota, subdivision Basidiomycotina (Bumpus and Aust,
1987). The P. chrysosporium BKMF-1767 (ATCC 24725) wild-type strain was originally isolated by T.I Novobranova, from plant species Vitis vinifera (Kazachstan, USSR) and was initially classified as Sporotrichum pulverulentum by Novobranova (Kirk et al., 1986). Of all the different WRF species studied, P. chrysosporium BKMF-1767 (ATCC 24725) was shown to produce the highest ligninase activity, compared to other WRF strains (Kirk et al., 1986; Linko, 1992).

The mechanisms involved in the degradation of lignin by the WRF are complex. As lignin is a three dimensional polymer, degradation by P. chrysosporium must take place as an extracellular process, using highly oxidative

\footnotetext{
* Author for correspondence: ntwampes@cput.ac.za
} 
mechanisms (Breen and Singleton, 1999), induced by nitrogen and carbohydrate starvation. The oxidative process is facilitated by the production of extracellular enzymes of which the catalytic activities have been studied using model lignin compounds (Kirk et al., 1986). Under ligninolytic conditions, P. chrysosporium produces two families of peroxidases, lignin peroxidases (LiP's) and manganese peroxidases (MnP's) in a $\mathrm{H}_{2} \mathrm{O}_{2}$ veratryl alcohol- $\mathrm{O}_{2}$ generating system. P. chrysosporium BKMF-1767 belongs to a minority of WRF that produce no detectable levels of laccase activity. The ligninolytic enzymes of $P$. chrysosporium are produced during secondary metabolism, when the biofilm is in the idiophase, an aspect identified as a major limitation for producing the enzymes in batch cultures. The performance of the biomass to produce the required enzymes in liquid cultures was shown to be dependent on the presence of readily metabolisable substrates such as glucose. Increasing the levels of glucose in liquid cultures, has been shown to have a strong activating effect on the rate of enzyme production, which was also influenced by the presence of manganese (Perie and Gold, 1991).

Several reviews and book chapters published by Eaton and Hale (1993), Highley and Dashek (1998), Leonowicz et al. (1999), Have and Teunissen (2001) and Hofrichter (2002), have covered the physiology, biochemistry and molecular biology aspects of $P$. chrysosporium, as well as the oxidative mechanisms of $\mathrm{LiP}$ and $\mathrm{MnP}$. Furthermore, Linko (1992) reviewed the bioprocessing aspects and other operational parameters that have been used for the production of LiP.

However, at present the following parameters have been inadequately covered: 1) oxidative stress and lipid peroxidation of $P$. chrysosporium biomass during enzyme production; 2) production of byproducts under anaerobic operational conditions; 3 ) the effect of extracellular glucan and polysaccharide production on dissolved oxygen (DO) mass transfer; 4) the possibility of trace metal accumulation in continuously operated bioreactors and 5) the effect of environmental stress on the development and performance of immobilised P. chrysosporium biomass in continuous fixed-film membrane bioreactors. This review provides a bioprocessing perspective to the improvements made thus far in the development of efficient batch reactor systems for the production of LiP and MnP enzymes from biofilms of $P$. chrysosporium. Shortcomings related to the employment of optimised batch reactor operational conditions for P. chrysosporium for continuous fixed-film membrane reactors are discussed.

\section{Conditions Used for Enhanced Ligninase Production in Submerged Batch Bioreactors}

Inoculum development and preparation for $P$. chrysosporium cultures

The preparation of an inoculum is performed by using conidia grown on malt agar slants, using a spore inducing media (SIM), as described by Tien and Kirk (1988). Currently, an inoculum of $P$. chrysosporium is generally prepared using two methods. Method 1 (preparation of seed culture); $P$. chrysosporium conidia are inoculated into small volumes of the nutrient media to cultivate mycelia. The spores are grown in $90 \mathrm{ml}$ of a nutrient media described by Tien and Kirk (1988) at $37^{\circ} \mathrm{C}$ in complete darkness for $48 \mathrm{~h}$. After four days the broth containing mycelia is homogenised in a blender for $1 \mathrm{~min}$ and $10 \% \quad(\mathrm{v} / \mathrm{v})$ of the homogenised mycelia is used as inoculum (Rivela et al., 2000; Rodríguez-Couto et al., 2000). Method 2 (preparation of spore solution): mycelia is cultivated on agar slants at $39^{\circ} \mathrm{C}$ for 1 to 2 weeks or up to 3 weeks (Lin et al., 1990). The spore suspensions are prepared from agar plates, using small volumes of sterile distilled water and a sterile spatula to detach the spores and mycelia from the agar. Thereafter, suspensions are repeatedly passed through autoclaved glass wool, using syringes, to separate the mycelia from the spores. The suspension is then used directly for inoculation without the addition of any nutrient media or it can be stored at $4{ }^{\circ} \mathrm{C}$ for subsequent inoculations. Stanbury et al. (1995) has provided detailed guidelines on inoculum preparations and development.

Nutrient media used for enhanced ligninase production with $P$. chrysosporium

The extracellular production of $\mathrm{LiP}$ and $\mathrm{MnP}$ has been studied using synthetic media based on the composition originally developed by Kirk et al. (1978). Other researchers modified this nutrient medium to suit their aims for ligninase production. Nitrogen limited (N-limited) nutrient medium has also been used and described by Tien and Kirk (1988). It is currently the preferred nutrient medium for ligninase production studies. There are 
four types of nutrient media compositions currently used for $\mathrm{LiP}$ and $\mathrm{MnP}$ production: 1) carbon limited (C-limited); 2) nitrogen limited (N-limited); 3) carbon excess (C-excess) and 4) nitrogen excess (N-excess) growth media. They are classified according to the ratio of the carbonnitrogen $(\mathrm{C} / \mathrm{N})$ content in the media, with glucose often being the carbon source, while different nitrogen sources have been used. The $\mathrm{C} / \mathrm{N}$ ratio can be used as a way to selectively produce LiP and $\mathrm{MnP}$. For example, when the ratio is low (Climited), the production of LiP is sustainable without the production of extracellular polysaccharides. However, when the $\mathrm{C} / \mathrm{N}$ ratio is high, increased concentrations of polysaccharides are produced, while LiP formation is induced only when technical grade $(100 \%)$ oxygen is used. Under N-excess conditions, LiP activity above $1000 \mathrm{UL}^{-1}$ can be achieved using air and $100 \%$ oxygen (Rothschild et al., 1995). This implies that by decreasing the glucose content in the production media, extracellular polysaccharide excretion and build-up in the mycelia can be limited, thus improving DO transfer through the biofilm. Moreira et al. (1997) designed a packed bed reactor, where the C-limited media was determined to have a positive effect on continuous extracellular LiP and MnP production.

The role of surfactants in the performance of $P$. chrysosporium biomass

The use of surfactants such as, Tween 80 , Tween 20, polyoxyethylene oleate and 3-[(3cholamidopropyl) dimethylammonio]-1-

propanesulfonate in the growth media used for $P$. chrysosporium cultures, enhanced ligninase production by 200 -fold after testing them as possible stimulators of ligninase activity (Jäger et al., 1985; Leštan et al., 1993). MnP was increased 260-fold (Novotný et al., 2004), after the addition of Tween 80 to submerged cultures. It was suggested that the extracellular enzymes of $P$. chrysosporium are weakly charged in their active state. This also means that ionic bonding is unlikely to be the retaining force in the production biomass. In the presence of a stronger binding force such as extracellular polysaccharide-based mucilage, P. chrysosporium biomass will entrap some of the enzymes.

It was determined that the enzymes were bound to the hyphae, thus the use of surfactants caused the release of the enzymes. Furthermore, surfactants have been shown to prevent the mechanical deactivation of ligninase as several surfactants were shown to protect the purified ligninase against mechanical agitation (Venkatadri and Irvine, 1990). Tween 80, as used in the N-limited medium at a final concentration of $0.05 \%(\mathrm{v} / \mathrm{v})$ has no inhibitory effects on fungal growth, whereas some surfactants such as Tergitol NP-10 and Triton X-100 inhibits the growth rate of P. chrysosporium by 75 to $95 \%$ (Ruiz-Aguilar et al., 2002).

\section{Bioreactor configurations and operating conditions used for ligninase production}

The production of LiP and MnP has been achieved in various types of reactors with different operating conditions, working volumes and operating times. The highest ligninase activities, greater than $1000 \mathrm{UL}^{-1}$ (Bonnarme et al., 1993; Doseretz et al., 1993; Rodríguez-Couto et al., 2001; Domínguez et al., 2001; Moldes et al., 2003), were achieved in bioreactor systems which used biofilm carriers/support and technical grade oxygen $(100 \%)$ or air to improve the enzyme production.

Previously reported bioreactor designs include a rotating drum reactor, achieving $1350 \mathrm{UL}^{-1}$ of $\mathrm{MnP}$ and $1400 \mathrm{UL}^{-1}$ of $\mathrm{LiP}$ production (Domínguez et al., 2001) and the immersion bioreactor achieving $1447 \mathrm{UL}^{-1}$ of $\mathrm{MnP}$ and 277 $\mathrm{UL}^{-1}$ of LiP (Rodríguez-Couto et al., 2001). These two bioreactors had a mobile mechanical device to move the biofilm to improve transfer of oxygen, while an N-limited nutrient medium was used. Another bioreactor design used for ligninase production consisted of a jacketed cylindrical glass vessel with a round bottom, containing a wire basket filled with polypropylene cubes. The baskets in the bioreactor were moving upwards and downwards using a pneumatic system, remaining $90 \mathrm{~s}$ outside and $10 \mathrm{~s}$ inside the nutrient medium (Rivela et al., 2000).

When $P$. chrysosporium was cultured in either cellulose or glucose as the carbon source, the synthesis of extracellular polysaccharides in the cultures was similar. The production of extracellular polysaccharides restricts the DO diffusion into the hyphae, which is necessary for LiP induction. It has been suggested that the requirement for agitation to improve DO transfer, is of paramount importance as LiP production is triggered by the response to oxidative stress or increased DO (Zacchi et al., 2000). 
Different types of reactors, without agitation devices, have also been evaluated for continuous $\mathrm{MnP}$ and/or LiP production. Examples of these reactors are trickle/packed bed, airlift and membrane bioreactors. Trickle bed reactors with different packing materials were evaluated for enzyme production as they had better DO and mass transfer capabilities. The trickle-bed bioreactor design was such that ligninasecontaining fraction was continuously removed and recycled. The operational conditions depend on the recycle ratio that is suitable for enhanced productivity. The reactor can be operated in semicontinuous and continuous modes, while the biomass carriers can be mobile due to liquid movement in the reactor, with some of the enzyme solution being recycled (Ruggeri and Sassi, 2003). However, the recycling of the ligninolytic fraction can inhibit and delay the production of LiP and $\mathrm{MnP}$ (Feijoo et al., 1995). The consequence of recycling ligninolytic enzyme fluids was less significant for submerged cultures, in which a decrease of $10 \%$ was observed in LiP activity, than for immobilised cultures, where a decrease of $50 \%$ occurred (Moreira et al., 1997). However, other researchers have indicated that LiP production was highest in packed-bed reactors with lower recycling ratios (2:1) (Feijoo et al., 1994), while the airlift reactor showed to provide a suitable low-shear environment for enzyme production by mycelial pellets. A simple method to produce LiP or MnP enzymes selectively was used by Bonnarme and Jefferies (1990a), by increasing either soluble $\mathrm{Mn}^{2+} / \mathrm{Mn}^{3+}$ organic acid complexes, to suppress $\mathrm{LiP}$ formation or to use $100 \% \mathrm{O}_{2}$ in Mn-deficient cultures to induce LiP, while suppressing $\mathrm{MnP}$, as indicated by Perez and Jeffries (1992).

Several studies have shown improved productivity using membrane bioreactors for the production of $\mathrm{LiP}$ and $\mathrm{MnP}$, with immobilised biofilms of P. chrysosporium (Venkatadri and Irvine, 1993; Leukes, 1999; Leukes et al., 1999; Solomon and Petersen, 2002; Govender et al., 2003; Govender et al., 2004; Sheldon and Small, 2005). The use of continuous fixed-film membrane bioreactors by Leukes et al. (1999), Solomon and Petersen (2002) , Govender et al., (2003), Govender et al., (2004) and Sheldon and Small (2005), where a biofilm of $P$. chrysosporium was immobilised on the external surface of a capillary membrane, showed potential for continuous extracellular enzyme production.
This reactor was classified as the Membrane Gradostat Reactor (MGR).

The industrial use of this type of reactor is hampered by DO and mass transfer limitations in the immobilised biofilm. However, the distinctive advantage is that they provide a suitable environment, which mimics the living conditions of microorganisms in their natural environment. The microorganism immobilised on the membranes find themselves in microenvironments containing nutrient gradients across the biofilm thickness. Due to the nutrient gradients, $P$. chrysosporium produces secondary metabolites as a large proportion of the fungal biofilm is kept in the idiophase. MnP production levels of $2361 \mathrm{UL}^{-1}$ was achieved by Leukes (1999) using the MGR bioreactor.

Since $P$. chrysosporium is a facultative aerobe, the fungus produces ethanol under anaerobic conditions (Kenealy and Dietrich, 2004), while the activity and the production of $\mathrm{LiP}$ and $\mathrm{MnP}$ is influenced by the availability of DO. The rate of lignin degradation by $P$. chrysosporium BKMF 1767 was reported to be 2 to 3 times higher by using technical grade oxygen $(100 \%)$ rather than air. This is despite the fact that growth is somewhat better in air (Kirk et al., 1978; Leisola et al., 1984). The ligninolytic system of the WRF has been shown to be particularly active in cultures, which are grown in high oxygen tension (Doseretz et al., 1993).

Faison and Kirk (1985) reported that ligninase production by $P$. chrysosporium was increased in cultures initially aerated with air during the primary growth phase of the fungus, before shifting to a technical grade oxygen $\left(100 \% \mathrm{O}_{2}\right)$ atmosphere. Prolonged exposure to high oxygen partial pressures may lead to hyperoxia, derived from enhanced intracellular formation of reactive oxygen species (ROS) (Li et al., 2004), but the formation of limited quantities of ROS has been shown to improve LiP induction (Belinky et al., 2005). From this information, it is clear that a delicate balance is required to limit ROS formation, while improving the longevity of active biomass in fixed-film bioreactors.

\section{Limitations Related to $P$. Chrysosporium Biomass Performance in Continuous Fixed- Film Bioreactors}


Metal accumulation and toxicity for immobilised P. chrysosporium biomass

WRF, including P. chrysosporium BKMF-1767, require trace amounts of essential heavy metals such as $\mathrm{Cu}, \mathrm{Mn}$ and $\mathrm{Fe}$ for its growth, including other trace elements described by Kirk et al. (1978), but these metals are toxic when present in excess. WRF have the capacity to adsorb and accumulate metal ions including $\mathrm{Cd}, \mathrm{Pb}, \mathrm{Ni}$, and Co (Falih, 1997; Baldrian, 2003). There is a risk of metal accumulation in continuous cultures even when the culture is only supplied with the growth media. Even in the case of $\mathrm{Mn}^{2+}$, the growth rate of P. chrysosporium is inhibited by $\mathrm{Mn}^{2+}$ concentrations from 150 to $300 \mathrm{mgL}^{-1}$ (Falih, 1998). When $\mathrm{Mn}^{2+}$ was not added to the production media for LiP production, the enzymes were formed in both $\mathrm{N}$-limited and $\mathrm{N}$-excess liquid culture exposed to air and was suppressed in cultures containing $\mathrm{Mn}^{2+}$ concentrations in excess of $13 \mathrm{mgL}^{-1}$. However, this was overcome in oxygen flushed, N-excess cultures with $\mathrm{Mn}^{2+}$ concentrations in the range of 3 to $1500 \mathrm{mgL}^{-1}$ (Rothschild et al., 1999). In some studies, $\mathrm{Mn}^{2+}$ was shown to have beneficial effects on immobilized biofilms of $P$. chrysosporium. Higher $\mathrm{MnP}$ activity was shown in cultures induced by heat shock and $\mathrm{Mn}^{2+}$, when compared with the cultures induced by $\mathrm{Mn}^{2+}$ alone (Brown et al., 1993), while complexes of $\mathrm{Cu}$ and $\mathrm{Fe}$ enhanced oxygen radical damage. However, the presence of $\mathrm{Mn}^{2+}$ in various forms was determined to inhibit ROS damage (Cheton and Archibald, 1988). Concentrations of $\mathrm{Mn}^{2+}$ above $50 \mu \mathrm{M}$ prevented chemical-supported lipid peroxidation measured by the production of malondialdehyde (MDA) (Tampo and Yonaha, 1992).

This suggests that in fixed-film continuous bioreactors, $\mathrm{Mn}^{2+}$ accumulation might regulate the excessive ROS production and limit $\mathrm{LiP}$ production. It was determined that in continuous membrane gradostat bioreactors, LiP production was limited for 1 to 5 days of bioreactor operation, while $\mathrm{MnP}$ took precedence thereafter (Leukes, 1999; Govender, 2000; Garcin, 2002). This effect might be caused by the production of polysaccharides, restricted DO transport and $\mathrm{Mn}^{2+}$ accumulation rather than ROS regulation. $\mathrm{Cu}$ accumulation was observed to cause oxidative damage to proteins by the induction of oxidative stress associated with the presence of ROS (Stohs and Bagchi, 1995), although low $\mathrm{Cu}$ concentrations $(0.0004$ to $1.2 \mu \mathrm{M})$ in the nutrient medium increased the activity of LiP and $\mathrm{MnP}$ of $P$. chrysosporium. Organic chelators, such as malonate and oxalate, are also metabolic bioproducts excreted by P.chrysosporium (Goodwin et al., 1994; Khindaria et al., 1994; Wesenberg et al., 2003), and they provide immobilisation of soluble ions or complexes to form insoluble oxalates. This also provides a tolerance mechanism to the accumulation of metals in P. chrysosporium. However, the effect of metal accumulation with increasing ionic strength in the basal medium should be investigated in more detail in continuous fixed-film bioreactors. The function of the nitrilotriacetate added to the trace element solution used for nutrient media preparation was to provide chelation therapy in case of metal accumulation in the P. chrysosporium biomass (Kirk et al., 1978).

\section{Dissolved oxygen mass transport limitations in biofilms of P. chrysosporium}

DO transport in $P$. chrysosporium biofilms is a limiting parameter for the production of both LiP and MnP. It was shown that DO limitation was the main reason for slow and incomplete lignin degradation (Kirk et al., 1978). When a DO Clarktype microsensor was used to quantify the DO in mycelial mats, the DO penetration depth was less than $1000 \mu \mathrm{m}$ even under cultures incubated under $100 \% \mathrm{O}_{2}$ at 1 atm (Leisola et al., 1983). DO penetration in pellets equilibrated in air-saturated culture fluid was $\sim 400 \mu \mathrm{m}$ (Michel et al., 1992). Oxygen limitation was also shown to be the main reason for slow, incomplete degradation of lignin in non-agitated cultures (Leisola et al., 1983). As DO transfer is limited to a depth of less than $1000 \mu \mathrm{m}$, oxygen limitation can result in the production of ethanol (Kenealy and Dietrich, 2004). Furthermore, the amount of DO levels decreases during the growth periods in cultures aerated with air and the oxygen uptake rate is highest during the period of 1 to 3 days. Venkatadri et al. (1992) determined that thinner biofilms are more efficient in LiP production and thus this effect can be directly linked to improved transportation of oxygen in thinner biofilms. The oxygen uptake rate for $P$. chrysosporium improved when Tween 80 was used in bioreactors operated for prolonged periods of more than 20 days. However, it was shown that the oxygen uptake rate between 0 to 10 days was better in cultures, which did not contain Tween 80, while cultures with Tween 80 showed increased oxygen uptake rates 
(4 times higher) from 20 to 40 days (Hodgson et al., 2000).

$P$. chrysosporium produces ethanol from glucose, mannose, cellobiose, maltose and sucrose when grown with limited oxygen. Under oxygen limited growth on glucose, low levels of acetate are also produced when the nitrogen content was limited or in excess. P. chrysosporium does not grow fermentatively, but survives transient oxygenlimitation by fermentation (Kenealy and Dietrich, 2004). MnP was shown to retain $20 \%$ of its normal activity in the presence of 45 to $58 \%(\mathrm{v} / \mathrm{v})$ acetone, 31 to $34 \%(\mathrm{v} / \mathrm{v})$ ethanol and 29\% 2-propanol. LiP was about 2 to 3 times less tolerant to these solvents compared to MnP (Field et al., 1996).

Proposed solutions for improvement of gaseous oxygen transport were: 1) to limit the biofilm thickness and 2) to increase pressure in the bioreactors where the biofilms are immobilised. In addition, when the biofilm thickness was restricted to the determined limiting thickness, the $P$. chrysosporium mycelial mats grown in air degraded lignin at the same rate comparable to that measured in $100 \% \mathrm{O}_{2}$ (Leisola et al., 1983). This means that the use of fixed-film bioreactors in which sufficient biofilm thickness is required to establish the areas with limited nutrients, the transport of DO will be limited.

The use of pressurised bioreactors to improve the DO transport in mycelial mats of P. chrysosporium was shown to improve DO transport, as lignin degradation in $5 \mathrm{~atm}$ of air was similar to that of oxygen in $1 \mathrm{~atm}$. It was also found that lignin degraded well in 2 atm $100 \% \mathrm{O}_{2}$ as in $1 \mathrm{~atm} 100 \% \mathrm{O}_{2}$, but under $3 \mathrm{~atm}$ pressure fungal growth was limited, while under 4 atm of $100 \% \mathrm{O}_{2}$, growth was restricted completely. This indicated that high oxygen concentration was the inhibiting factor to achieve sufficient biofilm growth (Reid and Seifest, 1980). However, the use of pressurised bioreactor systems to improve the DO transfer might not be effective for prolonged production periods, because of an increase in free and mycelial attached polysaccharides sheath in cultures where air and $100 \% \quad \mathrm{O}_{2}$ was used (Doseretz et al., 1993). Leisola et al. (1982) suggested that DO limitations were caused by excess polysaccharides production, identified as mucilaginous material made of $\beta$-glucans (Buchala and Leisola, 1987). When the atmosphere in a bioreactor of immobilised P. chrysosporium, was changed from air to $100 \% \mathrm{O}_{2}$, the thickening of extracellular glucan layer was observed after 2 to 3 days of bioreactor operation. The production of glucan is induced as an oxidative stress response and a defensive mechanism, i.e., the fungus produces extracellular glucan to limit DO diffusion to protect the cells from oxidative damage (Miura et al., 2004). Glucans are synthesized by a membrane-bound glucan synthase complex which uses glucose as a substrate (Latge and Calderone, 2006) and the glucans are used as a storage carbohydrate that facilitates growth by providing energy and carbon skeletons for protein synthesis (van Oijen et al., 2005), during nutrient limitation periods.

Long term effects of MnP-exposed $P$. chrysosporium biomass

Oxygen radical-mediated processes are wellknown to be involved in the peroxidation of lipids (Forney et al., 1982). Thus, it is not surprising that $\mathrm{MnP}$ can oxidise unsaturated lipids, causing the formation of lipoxyradicals intermediates (Breen and Singleton, 1999). These lipoxyradicals can cause increased lipid peroxidation in biomass depleted of nutrients in bioreactors operated for prolonged periods. The supernatants of WRF, contain a pro-oxidant or lipid peroxidation promoting activity, which is depended on the presence of $\mathrm{MnP}$ (Kapich et al., 2005). It was postulated that lipid peroxidation (a sign of oxidative stress) of highly unsaturated fungal membrane lipids could be coupled to lignin degradation in wood decaying Basidiomycetes fungus (Kapich, 1990) and that the entrapment of $\mathrm{MnP}$ in immobilised biomass initiated the formation of peroxyl and other lipid radicals (Kapich et al., 1990; Bao et al., 1994; Kapich et al., 1999). A high degree of lipid oxidative damage was detected in Mn-deficient LiP producing cultures of P. chrysosporium. This indicated intensive exposure to high concentrations of reactive oxygen species (ROS), which are typically found in oxygenated LiP-producing cultures. These observations reconfirmed the hypothesis that the induction of LiP expression was at least or partially mediated by the intracellular formulation of ROS (Belinky et al., 2005), while Mn deficiency increased the production of lipoxyradicals.

However, when $\mathrm{Mn}^{2+}$ is available as a free metal ion, it has the ability to act in the reverse mode of Fenton reactions, thus destroying free radicals. Furthermore, the $\mathrm{Mn}^{2+}$ ion acts as a cofactor in the formation of manganese-superoxide dismutase 
(Mn-SOD), which plays a role in the protection of cells against phospholipid peroxidation (Tampo and Yonaha, 1992; Have and Teunissen, 2001), by converting superoxide radicals into $\mathrm{H}_{2} \mathrm{O}_{2}$. Thus, $\mathrm{Mn}$ plays a regulatory role in $\mathrm{LiP}$ and $\mathrm{MnP}$ formation (Rothschild et al., 1999), limiting the level of oxygen radicals which have been suggested to play a major role in LiP formation, while acting as a substrate in the MnP cycle. When high levels of $\mathrm{Mn}^{2+}$ and $\mathrm{Mn}^{3+}$ ions are with a suitable chelator, $\mathrm{MnP}$ production is stimulated, while LiP production is suppressed (Perez and Jeffries, 1992).

Whatever the mechanisms of $\mathrm{H}_{2} \mathrm{O}_{2}$ production, intracellular catalase and Mn-SOD activities decrease during the secondary growth phase, while it can be anticipated that $P$. chrysosporium biomass will be more susceptible to oxidative damage during this growth phase in continuous fixed-film bioreactors. It has been shown that catalase levels inside the cell decrease at the end of the primary growth phase, while the peroxidase levels increase extracellularly (Morpeth, 1987). However, it was noted that primary and secondary growth phases were not distinguishable in wood grown mycelia, when compared to artificial liquid medium (Highley and Dashek, 1998), making it difficult to link catalase production levels with lignin degradation.

\section{CONCLUSIONS}

Bioprocess engineering considerations and challenges surrounding production of extracellular ligninase remain daunting. Effective measures are required to phase out batch/semi-batch type processes and to bring the development of fixedfilm continuous extracellular enzyme processes and bioreactors to the fore. This review showed that progress was made in describing the bioprocessing aspects related to bioreactor development for batch enzyme production. However, the aspects studied and optimised for submerged batch cultures should lead to limitations in continuous cultures. Since the development of continuous bioreactors seems a necessity for $\mathrm{LiP}$ and $\mathrm{MnP}$ production, the following parameters should be investigated further in fixed-film reactors: 1) determine the relationship between the amounts of glucan produced extracellularly in relation to DO kinetics in fixed-film bioreactors; 2) investigate the metal accumulation using the nutrient medium used by Tien and Kirk (1988) in continuous fixed-film reactors; 3) evaluate the use of liquid oxygen carriers in $P$. chrysosporium cultures and evaluate the oxidative damage in biofilms exposed directly to gaseous oxygen sources even at low oxygen partial pressures in fixed-film reactors.

\section{ACKNOWLEDGEMENTS}

This work was supported financially by the National Research Foundation of South Africa and DAAD (the German Academic Exchange Service) and the Carl and Emily Fuchs Foundation. The authors gratefully acknowledge Mr. B. Godongwana, Ms. C.C. Williams, Mr. A. Bester and Mrs. H. Small, for their assistance. The Cape Peninsula University of Technology librarians, Ms. Robyn Kerchhoff and Mr. Nazeem Abdurahman, are commended for their contribution in obtaining manuscripts used in this review.

\section{REFERENCES}

Baldrian, P. (2003), Interactions of heavy metals with white-rot fungi. Enzyme and Microbial Technology, 32, 78-91.

Bao, W., Fukushima, Y., Jensen, K. A., Moen, M. A. and Hammel, K. E. (1994), Oxidation degradation of non-phenolic lignin during lipid peroxidation by fungal manganese peroxidase. FEBS Letters, 354, 297-300.

Belinky, P. A., Flikshtein, N. and Doseretz, C. G. (2005), Induction of lignin peroxidase via reactive oxygen species in manganese-deficient cultures of Phanerochaete chrysosporium. Enzyme and Microbial Technology, 39, 222-228.

Bonnarme, P., Delattre, M., Drouet, H., Corrieu, G. and Asther, M. (1993), Toward a control of lignin and manganese peroxidases hypersecretion by Phanerochaete chrysosporium in agitated vessels: evidence of the superiority of pneumatic bioreactors on mechanically agitated bioreactors. Bioengineering and Biotechnology, 41, 440-450.

Breen, A. and Singleton, F. L. (1999), Fungi in lignocellulose breakdown and biopulping. Current Opinion in Biotechnology, 10, 252-258.

Brown, J. A., Li, D., Alic, M. and Gold, M. H. (1993), Heat shock induction of manganese peroxidase gene transcription in Phanerochaete chrysosporium. Applied and Environmental Microbiology, 59, 42954299. 
Buchala, A. J. and Leisola, M. (1987), Structure of beta-D-glucan secreted by $P$. chrysosporium in continuous culture. Carbohydrate Research, 165, 146-149.

Bumpus, J. A. and Aust, S. D. (1987), Biodegradation of environmental pollutants by the white rot fungus Phanerochaete chrysosporium: Involvement of the lignin degrading system. BioEssays, 6, 166-170.

Cheton, P. L.-B. and Archibald, F. S. (1988), Manganese complexes and the generation and scavenging of hydroxyl radicals. Free Radical Biology and Medicine, 5, 325-333.

Domínguez, A., Rivela, I., Rodríguez-Couto, S. and Sanromán, A. (2001), Design of a new rotating drum bioreactor for ligninolytic enzyme production by Phanerochaete chrysosporium grown on an inert. Process Biochemistry, 37, 549-554.

Doseretz, C. G., Rothschild, N. and Hadar, Y. (1993), Overproduction of Lignin Peroxidase by Phanerochaete chrysosporium (BKM-F-1767) under nonlimiting nutrient conditions. Applied and Environmental Microbiology, 59, 1919-1926.

Eaton, R. A. and Hale, M. D. C. (1993), Wood: Decay, pests, protection. Chapman and Hall, London.

Faison, B. D. and Kirk, T. K. (1985), Factors involved in the regulation of ligninase activity in Phanerochaete chrysosporium. Applied and Environmental Microbiology, 49, 299-328.

Falih, A. M. (1998), Impact of heavy metals on cellulolytic activity of some soil. Kuwait Journal of Science and Engineering, 25, 397-407.

Falih, A. M. (1997), Influence of heavy-metals toxicity on growth of Phanerochaete chrysosporium. Bioresource Technology, 60, 87-90.

Feijoo, G., Dosoretz, C. and Lema, J. M. (1994), Production of lignin peroxidase from Phanerochaete chrysosporium in a packed bed bioreactor with recycling. Biotechnology Techniques, 8, 363-368.

Feijoo, G., Rothschild, N., Dosoretz, C. G. and Lema, J. M. (1995), Effect of addition of extracellular culture fluid on ligninolytic enzyme formation in Phanerochaete chrysosporium. Journal of Biotechnology, 40, 21-29.

Field, J. A., Vledder, R. H., van Zelst, J. G. and Rulkens, W. H. (1996), The tolerance of lignin peroxidase and manganese-dependent peroxidase to miscible solvents and the in vitro oxidation of anthracene in solvent: water mixtures. Enzyme and Microbial Technology, 18, 300-308.

Forney, L. J., Reddy, C. A., Tien, M. and Aust, S. D. (1982), The involvement of hydroxyl radical derived from hydrogen peroxide in lignin degradation by the white-rot fungus Phanerochaete chrysosporium. Journal of Biological Chemistry, 257, 11455-11462.

Garcin, C. J. (2002), Design and manufacture of a membrane bioreactor for the cultivation of fungi. Unpublished MSc Thesis, Rhodes University, Grahamstown.
Gold, M. H. and Alic, M. (1993), Molecular biology of the lignin degrading Basidiomycete Phanerochaete chrysosporium. Microbiology Reviews, 57, 605-622.

Goodwin, D. C., Barr, D. P., Aust, S. D. and Grover, T. A. (1994), The role of oxalate in lignin peroxidasecatalysed reduction: protection from compound III accumulation. Archives of Biochemistry and Biophysics, 315, 267-272.

Govender, S. (2000), Optimisation studies on a membrane gradostat bioreactor for ligninase production using white rot fungi. Unpublished MTech Thesis, ML Sultan Technikon, Durban

Govender, S., Jacobs, E. P., Leukes, W. D., Odhav, B. and Pillay, V. L. (2004), Towards an optimum spore immobilisation strategy using Phanerochaete chrysosporium, reverse filtration and ultrafiltration membranes. Journal of Membrane Science, 238, 8392.

Govender, S., Leukes, W. D., Jacobs, E. P. and Pillay, V. L. (2003), A scalable membrane gradostat reactor for enzyme production using Phanerochaete chrysosporium. Biotechnology Letters, 25, 127-131.

Have, R. T. and Teunissen, P. J. M. (2001), Oxidative mechanisms involved in lignin degradation by Whiterot fungi. Chemical Reviews, 101, 3397-3413.

Highley, T. L. and Dashek, W. V. (1998), Biotechnology in the study of Brown and White-rot fungi. In Forest products Biotechnology (Eds). A. Bruce and Palfreyman J.W. Taylor and Francis, London, pp. 15-36.

Hodgson, J., Rho, D., Guiot, S. R., Ampleman, G., Thiboutot, S. and Hawari, J. (2000), Tween 80 enhanced TNT mineralisation by Phanerochaete chrysosporium. Canadian Journal of Microbiology, 46, 110-118.

Hofrichter, M. (2002), Review: Lignin conversion by manganese peroxidase (MnP). Enzyme and Microbial Technology, 30, 454 - 466.

Jäger, A., Croan, S. and Kirk, T. K. (1985), Production of ligninases and degradation of lignin in agitated submerged cultures of Phanerochaete chrysosporium. Applied and Environmental Microbiology, 50, 12741278.

Kapich, A. N., Hofrichter, M., Vares, T. and Hatakka, A. (1999), Coupling of manganese peroxidase mediated lipid peroxidation with destruction of nonphenolic lignin model compounds and ${ }^{14} \mathrm{C}$-labelled lignins. Biochemical and Biophysical research Communications, 259, 212-219.

Kapich, A. N., Steffen, K. T., Hofrichter, M. and Hatakka, A. (2005), Involvement of lipid peroxidation in the degradation of a non-phenolic lignin model compound by manganese peroxidase of the litter-decomposing fungus Stropharia coronilla. Biochemical and Biophysical research Communications, 330, 371-377.

Kapich, A. N. (1990), Biosynthetic activity of woodrotting Basidiomycetes in submerged culture. 
Mikologiya i Fitopatologiya, 24, 377-384 (written in Russian, translated to English).

Kapich, A. N., Romanovetz, E. S. and Voit, S. P. (1990), Content and composition of lipids in mycelium of wood-rotting Basiodiomycetes. Mikol. Fitopatol., 24, 51-56 (in Russian).

Kenealy, W. R. and Dietrich, D. M. (2004), Growth and fermentation responses of Phanerochaete chrysosporium to $\mathrm{O}_{2}$ limitation. Enzyme and Microbial Technology, 34, 490-498.

Khindaria, A., Grover, T. A. and Aust, S. D. (1994), Oxalate-dependent reductive activity of manganese peroxidase from Phanerochaete chrysosporium. Archives of Biochemistry and Biophysics, 314, 301306.

Kirk, T. K., Tien, M., Johnsrud, S. C. and Eriksson, K. (1986), Lignin degradation activity of Phanerochaete chrysosporium Burds: comparison of cellulosenegative and other strains. Enzyme and Microbial Technology, 8, 75 - 80.

Kirk, T. K., Schultz, E., Connors, W. J., Lorenz, L. F. and Zeikus, J. G. (1978), Influence of culture parameters on lignin metabolism by Phanerochaete chrysosporium. Archives of Microbiology, 117, 277285.

Latge, J. P. and Calderone, R. (2006), The fungal cell wall. In Growth, Differentiation and Sexuality. Vol. 1 (Eds). U. Kues and Fischer R. Springer, New York, pp. 73 - 104.

Leisola, M., Ulmer, D. C. and Fiechter, A. (1984), Factors affecting lignin degradation in lignocelluloses by $P$. chrysosporium. Archives of Microbiology, 137, 171-175.

Leisola, M., Ulmer, D. C. and Fiechter, A. (1983), Problem of oxygen transfer during degradation of lignin by Phanerochaete chrysosporium. European Journal of Applied Microbiology and Biotechnology, 17, 113-116.

Leonowicz, A., Matuszewska, A., Luterek, J., Ziegenhagen, D., Wojtas-Wasilewska, M., Cho, N., Hofrichter, M. and Rogalski, J. (1999), Biodegradation of lignin by White-rot fungi. Fungal Genetics and Biology, 27, 175-185.

Leštan, D., Černilec, M., Štrancar, A. and Perdih, A. (1993), Influence of some surfactants and related compounds on ligninolytic activity of Phanerochaete chrysosporium. FEMS Microbiology Letters, 106, $17-$ 22.

Leukes, W. (1999), Development and characterization of a membrane gradostat bioreactor for the bioremediation of aromatic pollutants using white rot fungi. PhD Thesis, Rhodes University, Grahamstown.

Leukes, W. D., Jacobs, E. P., Rose, P. D., Sanderson, R. D. and Burton, S. G. (1999), Method of producing secondary metabolites. USA patent 5945002.

Li, J., Gao, X., Qian, M. and Eaton, J. W. (2004), Mitochondrial metabolism underlies hyperoxic cell damage. Free Radical Biology and Medicine, 36, 1460-1470.

Lin, J.-E., Wang, H. Y. and Hickey, R. F. (1990), Degradation of pentachlorophenol by Phanerochaete chrysosporium. Biotechnology and Bioengineering, 35, $1125-1134$.

Linko, S. (1992), Production of Phanerochaete chrysosporium lignin peroxidase. Biotechnology Advance, 10, 191-236.

Michel, F. C., Grulke, E. A. and Reddy, C. A. (1992), Determination of the respiration kinetics for mycelial pellets of Phanerochaete chrysosporium. Applied and Environmental Microbiology, 58, 1740-1745.

Miura, D., Tanaka, H. and Wariishi, H. (2004), Metabolomic differential display analysis of the White-rot Basidiomycete Phanerochaete chrysosporium grown under air and $100 \%$ oxygen. FEMS Microbiology Letters, 234, 111-116.

Moldes, D., Rodríguez-Couto, S., Cameselle, C. and Sanromán, A. (2003), Study of the degradation of dyes by $\mathrm{MnP}$ of Phanerochaete chrysosporium produced in a fixed-bed bioreactor. Chemosphere, 51, 295-303.

Moreira, M. T., Feijoo, G., Palma, C. and Lema, J. M. (1997), Continuous production of manganese peroxidase by Phanerochaete chrysosporium immobilised on polyurethane foam in a pulsed packed-bed reactor. Biotechnology and Bioengineering, 56, 130-137.

Morpeth, F. F. (1987), Intracellular oxygenmetabolising enzymes of Phanerochaete chrysosporium. Journal of General Microbiology, 133, 3521-3525.

Novotný, C., Svobodová, K., Erbanová, P., Cajthaml, T., Kasinath, A., Lang, E. and Šašek, V. (2004), Ligninolytic fungi in bioremediation: extracellular enzyme production and degradation rate. Soil Biology and Biochemistry, 36, 1545 - 1551.

Perez, J. and Jeffries, T. W. (1992), Roles of manganese and organic acid chelators in regulating lignin degradation and biosynthesis of peroxidases by Phanerochaete chrysosporium. Applied and Environmental Microbiology, 58, 2402-2409.

Perie, F. H. and Gold, M. H. (1991), Manganese regulation of manganese peroxidase expression and lignin degradation by the White-rot fungus Dichomitus squalen. Applied and Environmental Microbiology, 57, 2240-2245.

Reid, I. D. and Seifest, K. A. (1980), Lignin degradation by Phanerochaete chrysosporium in hyperbaric oxygen. Canadian Journal of Microbiology, 26, 1168-1171.

Rivela, I., Rodríguez-Couto, S. and Sanromán, A. (2000), Extracellular ligninolytic enzyme production by Phanerochaete chrysosporium in a new solid-state bioreactor. Biotechnology Letters, 22, 1443-1447.

Rodríguez-Couto, S., Rivela, I., Munoz, M. R. and Sanromán, A. (2000), Stimulation of ligninolytic 
enzyme production and the ability to decolourise Poly R-478 in semi-solid-state cultures of Phanerochaete chrysosporium. Bioresource Technology, 74, 159164.

Rodríguez-Couto, S., Ratto, M., Dominguez, A. and Sanromán, A. (2001), Strategies for improving ligninolytic enzyme activities in semi-solid-state bioreactors. Process Biochemistry, 36, 995-999.

Rothschild, N., Hadar, Y. and Dosoretz, C. G. (1995), Ligninolytic system formation by Phanerochaete chrysosporium in air. Applied and Environmental Microbiology, 61, 1833-1838.

Rothschild, N., Levkowitz, A., Hadar, Y. and Dosoretz, C. G. (1999), Manganese deficiency can replace high oxygen levels needed for lignin peroxidase formation by Phanerochaete chrysosporium. Applied and Environmental Microbiology, 65, 483-488.

Ruggeri, B. and Sassi, G. (2003), Experimental sensitivity analysis of a trickle bed bioreactor for lignin peroxidases by $P$. chrysosporium. Process Biochemistry, 38, 1669-1676.

Ruiz-Aguilar, G. M. L., Fernández-Sánchez, J. M., Rodríguez-Vázquez, R. and Poggi-Varaldo, $\mathrm{H}$. (2002), Degradation by White-rot fungi of high concentrations of PCB extracted from a contaminated soil. Advances in Environmental Research, 6, 559568.

Sheldon, M. S. and Small, H. J. (2005), Immobilisation and biofilm development of Phanerochaete chrysosporium on polysulphone and ceramic membranes. Journal of Membrane Science, 263, 3037.

Solomon, M. S. and Petersen, F. W. (2002), Membrane bioreactor production of lignin and manganese peroxidase. Membrane Technology, 144, 6- 8.

Stanbury, P. F., Whitaker, A. and Hall, S. J. (1995), Principles of Fermentation technology. ButterworthHeinemann, London.
Stohs, S. J. and Bagchi, D. (1995), Oxidative mechanisms in the toxicity of heavy metals. Free Radical Biology and Medicine, 18, 321-336.

Tampo, Y. and Yonaha, M. (1992), Antioxidant mechanism of $\mathrm{Mn}(\mathrm{II})$ in phospholipid peroxidation. Free Radical Biology and Medicine, 13, 115-120.

Tien, M. and Kirk, T. K. (1988), Lignin peroxidase of Phanerochaete chrysosporium. Methods in Enzymology, 161, 238-249.

van Oijen, T., Veldhuis, M. J. W., Gorbunov, M. Y., Nishioka, J., van Leeuwe, M. A. and de Baar, H. J. W. (2005), Enhanced carbohydrate production by Southern Ocean phytoplankton in response to in situ iron fertilization. Marine Chemistry, 93, 33-52.

Venkatadri, R. and Irvine, R. L. (1993), Cultivation of Phanerochaete chrysosporium and production of lignin peroxidase in novel biofilm reactor system: Hollow fibre reactor and silicon membrane reactor. Water Research, 27, 591-596.

Venkatadri, R. and Irvine, R. L. (1990), Effect of agitation on ligninase activity and ligninase production by Phanerochaete chrysosporium. Applied and Environmental Microbiology, 56, 26842691.

Wesenberg, D., Kyriakides, I. and Agathos, S. N. (2003), White-rot fungi and their enzymes for the treatment of industrial effluents. Biotechnology Advances, 22, 161-187.

Zacchi, L., Burla, G., Zuolong, D. and Harvey, P. J. (2000), Metabolism of cellulose by Phanerochaete chrysosporium in continuously agitated culture is associated with enhanced production of Lignin peroxidase. Journal of Biotechnology, 78, 185-192.

\footnotetext{
Received: February 28, 2008; Revised: August 14, 2008; Accepted: December 01, 2009.
} 